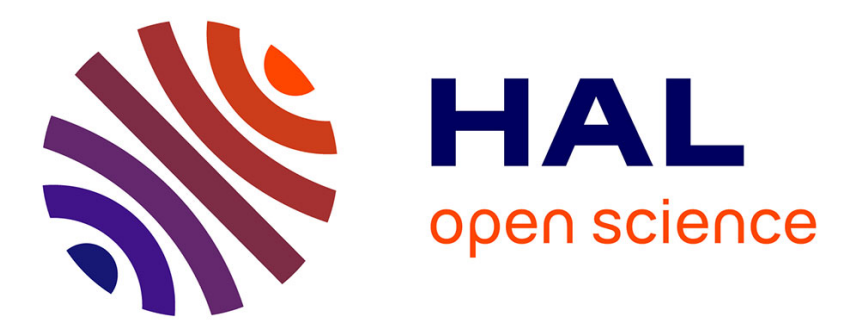

\title{
THE DYNAMIC PROPERTIES OF TWO-PHASE ALUMINA/GLASS CERAMICS
}

Y. Yeshurun, Dg. Brandon, A. Venkert, Z. Rosenberg

\section{To cite this version:}

Y. Yeshurun, Dg. Brandon, A. Venkert, Z. Rosenberg. THE DYNAMIC PROPERTIES OF TWOPHASE ALUMINA/GLASS CERAMICS. Journal de Physique Colloques, 1988, 49 (C3), pp.C3-11C3-18. 10.1051/jphyscol:1988302 . jpa-00227718

\section{HAL Id: jpa-00227718 https://hal.science/jpa-00227718}

Submitted on 1 Jan 1988

HAL is a multi-disciplinary open access archive for the deposit and dissemination of scientific research documents, whether they are published or not. The documents may come from teaching and research institutions in France or abroad, or from public or private research centers.
L'archive ouverte pluridisciplinaire HAL, est destinée au dépôt et à la diffusion de documents scientifiques de niveau recherche, publiés ou non, émanant des établissements d'enseignement et de recherche français ou étrangers, des laboratoires publics ou privés. 


\author{
Y. YESHURUN* ${ }^{*}$ D.g. BRANDON, A. VENKERT and Z. ROSENBERG* \\ Department of Materials Engineering, Technion - Israel Institute \\ of Technology, IL-Haifa 32000, Israel \\ "RAFAEL, ADA, PO BOX 3250, Haifa, Israel
}

Résumé - Les propriétés dynamiques des céramiques monolytiques se dégradent habituellement en présence d'une seconde phase. La différence d'impédance des constituants est le principal facteur responsable des dommages microstructuraux aux interfaces de phase. Des essais de restauration sous chocs ont montré que pour les alumine/verre, les microfissures étaient initiées à un niveau de contrainte inférieur à celui de la contrainte a rupture dynamique.

Les premières microfissures ne sont pas liées entre elles et l'échantillon conserve sa rigidité élastique en dépit de sa perte de résistance à l'écaillage, qui, elle, est associee au dommage microstructural. La microfissuration a pour conséquence des concentrations locales de contraintes résiduelles et des échauffements locaux qui accompagnent la relaxation de l'énergie élastique. La multiplication des dislocations et des glissements, une déformation plastique et une redistribution des differentes phases vitreuses, ainsi qu'une recristallisation partielle de la phase vitreuse sont parmi les conséquences de cet échauffement local.

\begin{abstract}
The dynamic properties of monolithic ceramics are in general degraded by the presence of a second phase. Impedance mismatch is the primary factor responsible for microstructural damage in the region of the phase boundaries. Planar shock recovery experiments have shown that microcracks in alumina/glass are generally initiated at a stress level below the observed dynamic failure stress. The initial microcracks are unconnected and the sample retains elastic rigidity. in spite of the loss of spall strength associated with the microstructural damage. Microcracking results in local residual stress concentrations and local heating which accompany the elastic energy release. Dislocation multiplication and glide, the flow and redistribution of any glassy phase, and partial crystallisation of the glass are among the possible consequences of this local heating.
\end{abstract}

\title{
1 - INTRODUCTION
}

A number of microstructural mechanisms have been proposed to explain the dynamic behaviour of ceramic materials. Typically, at shock stresses above the Hugoniot elastic limit (HEL) the stress profile consists of a discontinuous jump at the HEL (6 GPa for AD85 alumina /1/), followed by a dispersive wave. This behaviour is in contrast to the more familiar two-wave structure associated with ductile metals. The most generally accepted hypothesis proposed to account for the dispersive wave is the onset of microcracking /2/, which has also been suggested as the factor responsible for the HEL in ceramic materials. Alternative possibilities are either the onset of dislocation multiplication and the associated plastic shear, or incipient melting which is induced by local adiabatic heating. The latter process seems inherently unlikely except at very high shock pressures, although local heating associated with plastic shear could certainly give rise to the softening of a second glassy phase. 
Grady /3/ has considered criteria for the generation of localised hot-spots induced by plastic shear and has shown how the development of these instabilities depends on the physical properties of the ceramic, especially the specific heat and thermal conductivity. Grady arrives at an empirical model for shear instabilities based on an assumed temperature-dependent viscosity and on the calculated thermal diffussivity of the material. This enables him to derive a characteristic spacing for the instabilities as well as their characteristic growth rate. Both parameters depend on the imposed strain rate.

Longy and Cagnoux /4/ have demonstrated that microcracking is an important feature of failure in an alumina containing approximately $10 \%$ of a glassy phase at impact pressures exceeding the HEL, but no microcracking was observed in a monolithic alumina, containing less than $1 \%$ glass, until the impact pressure exceeded the HEL by a factor of two. These observations were based on scanning electron microscopy of spalled fragments recovered from a planar impact gas gun experiment, and are in contrast to the observations of the authors /5/, who have demonstrated that microcrack formation in an AD8S alumina, which contains $30 \%$ anorthite glass, is initiated well below the HEL, with a microcrack density increasing steadily with shock pressure. These results thus suggest a possible relationship between the shock pressure for the initiation of microcracking and the volume fraction of the second, glassy phase. Two further factors should also be considered: Firstly, these pressureless sintered aluminas contain various volume fractions of residual porosity (up to $10 \%$ ), so that dynamic compaction could be an important feature of the shock wave events. Secondly. the observation of a HEL implies a reduction of shear stress at a critical shock pressure. Some cumulative damage criterion is therefore required to account for the HEL. The results obtained indicate only that there is a clear difference between the damage process in a monolithic alumina ceramic and that in a material containing a second, glassy phase.

In the present contribution we present recent observations on the various features of the microstructural damage observed in specimens of glass-containing alumina recovered after planar impact. in the expectation that these post-mortem observations may throw more light on the cumulative damage processes resposible for failure. We also discuss the dynamic features of shock wave propagation associated with the impedance mismatch between the constituent phases of a two-phase ballistic ceramic.

\section{2 - EXPERIMENTAL}

Specimens of commercial AD85 and Armorflex aluminas were embedded in steel momentum traps in the configuration developed by DeCarli and Meyers /6/. A typical arrangement is shown in fig.1. The steel momentum traps have almost the same impedance as the alumina specimens, thus minimising the impedance mismatch within the specimen assembly and ensuring that the specimen was subjected to a planar pressure pulse with no subsequent tensile release wave loading. Recovered specimens subjected to pulse pressures of up to 7 GPa (close to and above the HEL) were examined by both scanning and transmision electron microscopy (SEM and TEM).

The specimen discs were cut from $12 \mathrm{~mm}$ thick rectangular tiles. The faces were lapped to ensure good contact with the steel momentum traps (fig.1). Both grades of alumina consist of a matrix phase of $\alpha-A l z O=$ which is interpenetrated by a continuous three-dimensional network of a glassy phase. This glassy phase is located primarily at the grain boundary junctions. The total glass content is approximately 30 vol\% 
in AD85, but only 12 vol\% in the Armorflex material. The densities of the two materials were 3.41 and $3.56 \mathrm{gm} . \mathrm{cm}^{-3}$ respectively, while the longitudinal sound wave velocities, as determined from ultrasonic measurements, were 8.8 and $9.0 \mathrm{~mm} . \mu \mathrm{s}^{-1}$. Both materials contained some residual porosity - up to 10 vol\% in the case of AD85.

\section{3 - RESULTS}

As noted in previous work /5/, there is an apparent threshold for the onset of microcracking in AD85 at about 3 GPa. A similar threshold has now been found in the Armorflex material, at about 5.5 GPa (corresponding to $80 \%$ of the HEL for this ceramic). These results are summarised in fig.2. Fig.3 shows an example of the microcracks observed in AD85 at a shock pressure of $6.5 \mathrm{GPa}$. The detection of a microcrack is dependent on the means of observation, and a higher density of microcracks would be expected to be visible when using the higher resolution of the TEM. In particular, incomplete microcracking associated with the detailed microstructural topography was found to be readily detected in thin films prepared for TEM, but was not unambiguously identified by SEM.

A general feature of the failure process was the extensive viscous flow of the glassy phase in the region of the microcracks, as noted in our previous report /5/. In general, the width of the microcracks (the microcrack opening displacement) was observed to be almost entirely due to this viscous flow at the crack tip. Again, as noted previously, the actual failure processes were not confined to a single fracture plane, but occured in a region of cumulative damage some three or four grains thick $(10$ to $15 \mu \mathrm{m})$, in which extensive cavitation was also associated with viscous flow of the glassy phase.

The TEM unit could, in addition to the TEM mode, also be operated in either a high resolution SEM mode or in a scanning transmission (STEM) mode. By using these alternative imaging modes on the same region of the same specimen. the results obtained by transmission electron microscopy could be directly linked to those which we have reported previously using the scanning electron microscope /5/. Microcracks were readily visible in the thin films using all three imaging modes (TEM, SEM and STEM). Fig. 4 presents an example for a specimen of AD85 impacted at $6.8 \mathrm{GPa}$ and shows both the SEM (fig.4a) and STEM images (fig. $4 \mathrm{~b}$ ).

All the microcracks which have been observed were found to have dimensions related to the grain size and were arrested by the grain topography. Furthermore, for all practical purposes the cracks were limited to the glassy phase and the region of the interface between the glassy phase and the $\alpha-\mathrm{Al}_{2} \mathrm{O} 3$. As noted in our previously /5/, blunting of the microcracks occurred by viscous flow of the glass. which also appeared to be the dominant mechanism for the production of the low density damage zone in the region of the spall failures previously studied.

From the TEM observations two further modes of impact damage were distinguished which were not susceptible to observation in SEM. The first is regions of dislocation activity in certain grains of $\alpha-\mathrm{Al}_{2} \mathrm{O}=$. often apparently associated with the tip of a blocked microcrack. An example is shown in fig.5. The second phenomenon which has been noted is the presence of some regions in which the glassy phase appears to have undergone some form of disintegration or microcrystallisation. An example of this phenomenon is shown in fig.6. In fig.6a an arrested microcrack is observed ending in the glassy phase. In fig.6b the region at the tip of the crack is seen at a higher magnification, and the breakup and apparent crystallisation are clearly evident. These "particles" are quite different from those sometimes observed in the 
glassy phase of well-annealed samples, which were readily identified as either anorthite or, rarely, cordierite or spinel.

\section{4 - DISCUSSION}

The propagation of a planar elastic shockwave in a two-phase solid will be accompanied by dispersion phenomena associated with the mismatch in the longitudinal soundwave velocity $C_{L}$, the dynamic impedance (which determines the particle velocity $u_{p}$ ) and the dynamic elastic strain $\epsilon_{d}=u_{p} / C_{L}$. The extent of these dispersion effects will depend on the scale of the microstructure, that is the average grainsize $D$, and the volume fraction of the second phase $f_{w}$. The mismatch in $C_{L}$ will tend to make the shockwave diffuse and will give rise to shear forces at particle boundaries /7/. The effect will be limited to distances of the order of the grainsize. Although the expected shear stresses can be very large, depending on both the extent of the mismatch and the grainsize, the threshold for the generation of damage is expected to depend on the energy which can be released in the region of the individual grains. Shockwave focussing at curved particle boundaries would modify the effect of the mismatch, but should not change the general picture.

Two limiting conditions for the generation of microstructural damage by impedance mismatch are possible. corresponding to phase boundaries which are either parallel or perpendicular to the direction of shockwave propagation. For phases aligned in parallel the particle velocities in the two phases will be constrained to match, and the applied pressure will be partitioned in the ratio of the impedances. At phase boundaries which are perpendicular to the direction of shockwave propagation, the shock wave will always be partially reflected at the boundary because of the particle velocity mismatch, tending to promote phase separation and fracture at the boundary. In the two materials studied both the alumina and the glassy phases exist as three-dimensional interpenetrating networks, as suggested by the model discussed by Nielson /8/ (fig.7). A shock wave moving through such a microstructure may be expected to deviate from the planar configuration on the scale of the microstructure, giving rise to interfacial shear stresses at the phase boundaries $/ 7 /$.

The above considerations lead to the following possible model for the microdynamic events associated with impedance mismatch. Consider each of the two phases to be embedded in material of "average" properties, such that each phase behaves as though it were subjected to impact by "average" material. This is illustrated in fig. 8 , which gives a schematic Hugoniot diagram for a two-phase material ( $A+B)$ impacted by a projectile which gives rise to an average particle velocity $u_{p}{ }^{*}$ and pulse pressure $\mathrm{P}^{*}$. Within the bulk of the target the individual grains are assumed to behave as though the particle velocities and pulse pressures were distributed about mean values, determined from the intercept of the (A+B) Hugoniot (as "impactor") with the individual A and B Hugoniots (as "targets"). The expected spread of values ( $\delta P$ and $\delta u_{m=x}$ ) should lie within the bounds set by assuming either constant particle velocity or constant pressure conditions for phase boundaries lying either parallel or perpendicular to the direction of propagation of the propagation.

Impedance mismatch effects are expected to be localised at the shockwave front and to lead to "damage" on the scale of the microstructure. The form of the damage - microcracking, dislocation generation, viscous flow or phase transformations - will depend on the time constants for the material response and on the microstructural dimensions. In the present alumina/glass materials microcracking is 
considered to be the primary form of the damage. since alternative processes are expected to give slower energy release rates. However, the energy released by microcracking will itself lead to secondary processes. Localised heating, in particular, will result in viscous flow of the glassy phase and the subsequent blunting of arrested microcracks. This blunting process will occur behind the initial shock front in the region of the thermal spike emitted at the moment of microcrack formation. The duration of the thermal spike is limited by the thermal diffusivity and may exceed the duration of the pressure pulse, so that stress relaxation continues into the domain of the release wave.

The microcrack thresholds which have been observed so far are compared with those found by Longy and Cagnoux in fig.9 on the basis of both the HEL and the bulk density (which is a function of the glass content). The present model suggests that to optimise the microstructural design of a two-phase ceramic we should minimise the impedance mismatch of the constituent phases and reduce the grainsize, possibly to the sub-micron regime. Porosity is expected to be a major factor in degrading the dynamic properties. Since it is impossible to avoid phase mismatch in all the relevant physical properties of the constituent phases, some localised damage associated with shear stresses at the phase boundaries is inevitable. The extent of this damage will then depend on the volume fraction of the second phase.

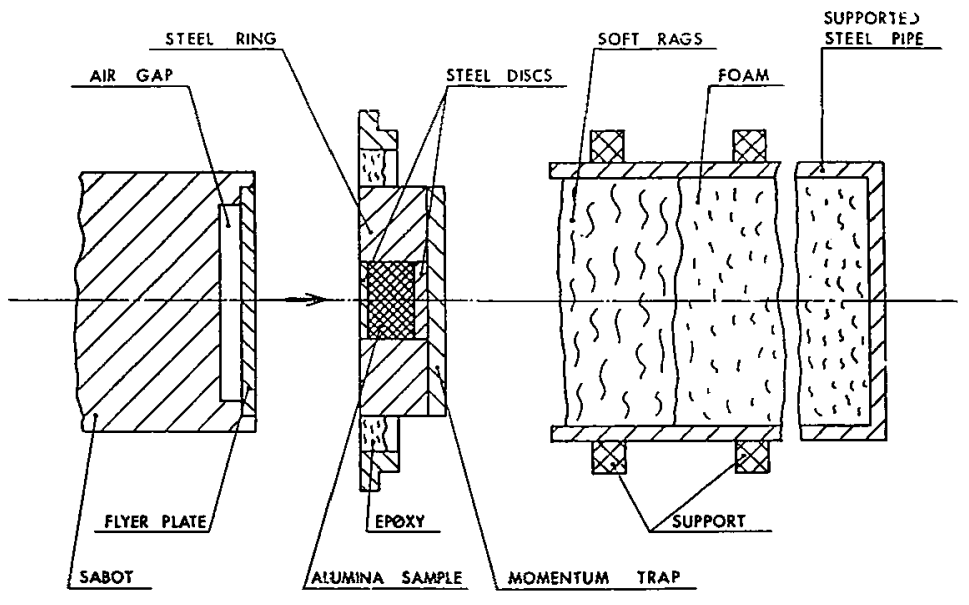

Fig.1 - Projectile and specimen assemblies and soft recovery chamber. 

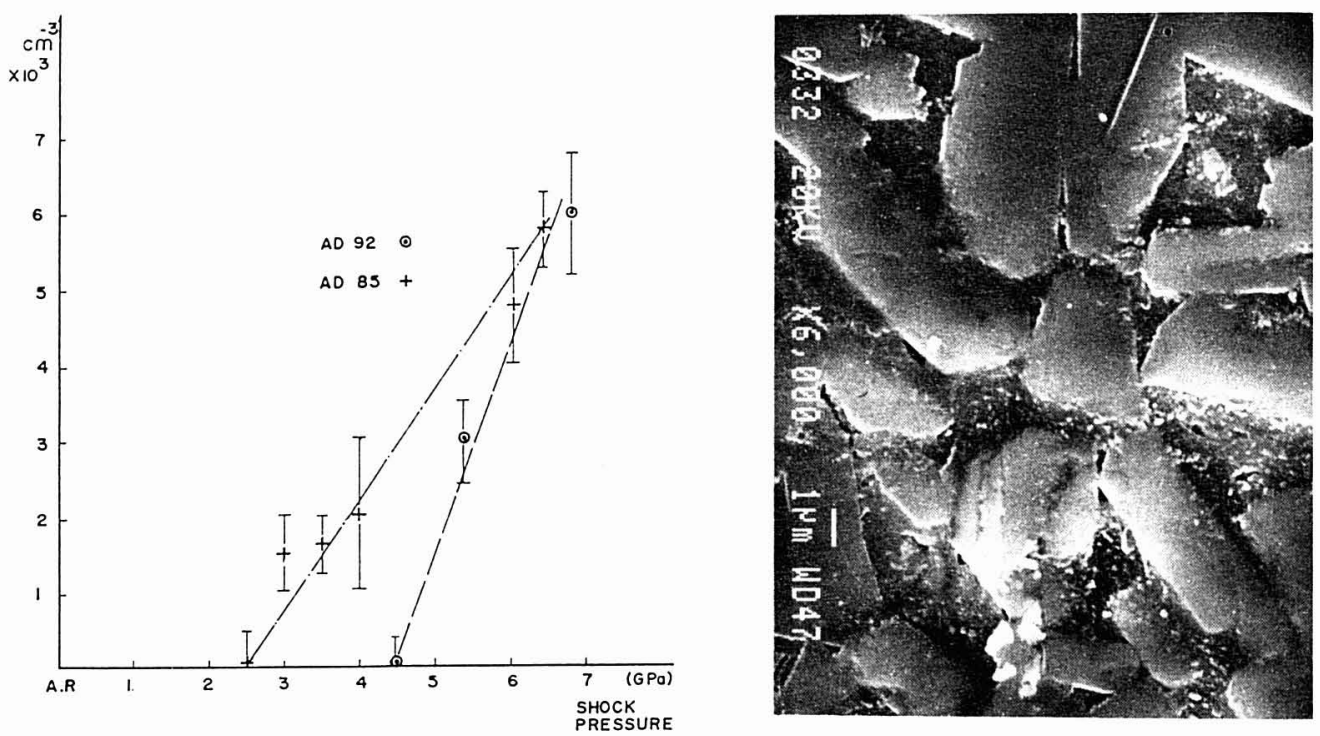

Fig.2 - Estimated microcrack densities for the two alumina/glass ceramics as a function of the shock pressure.

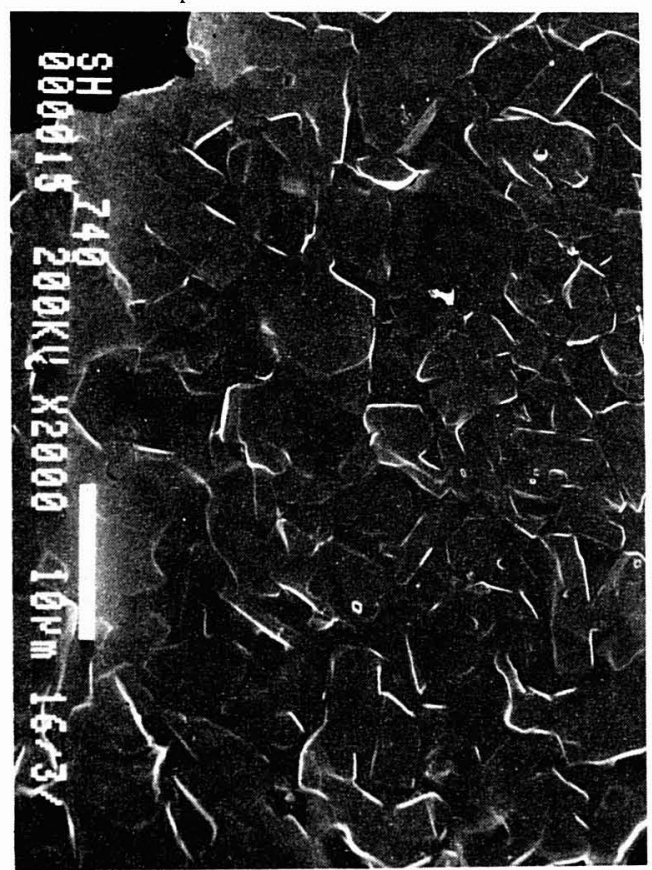

Fig.3 - Microcracks located at the alumina/glass phase boundaries in A085 (5.8 GPa shock pressure).

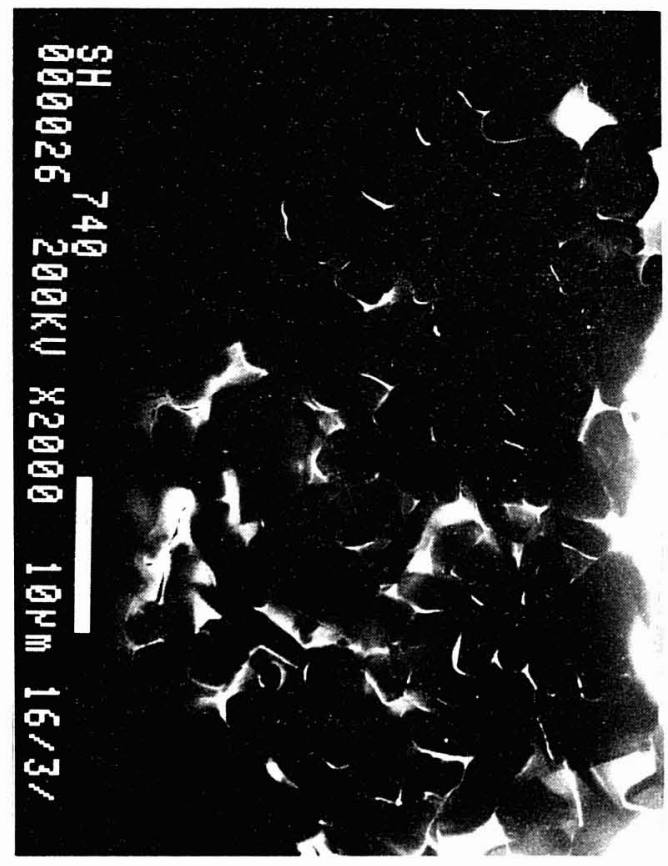

Fig. 4 - Microcracked region examined in SEM and STEM modes. AD85. 6.8 GPa shock pressure (a) SEM image (b) STEM image 


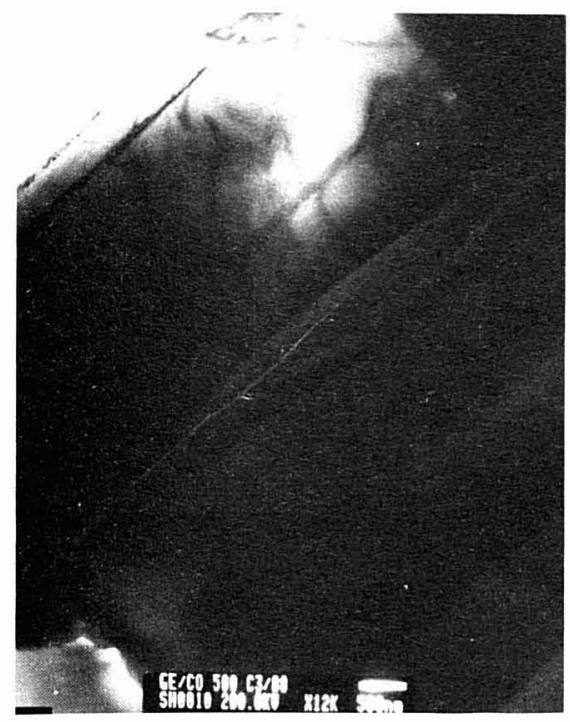

Fig.5 - Dislocations in $\alpha-\mathrm{Al}_{2} \mathrm{O}_{3}$ generated at a crack tip.

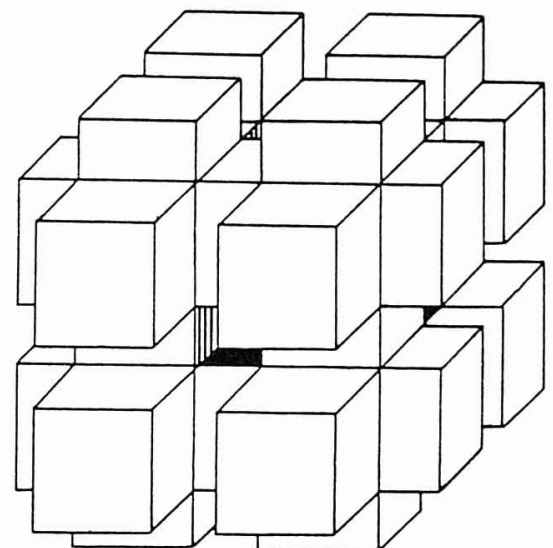

Fig.7 - Proposed microstructural model for two-phase ceramics (after Nielsen $/ 8, /$ ).

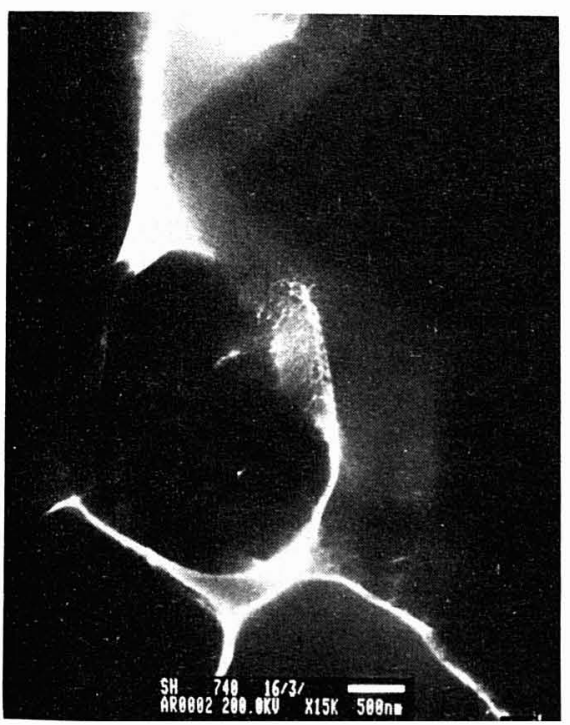

Fig. 6 "Microcrystallised" magnification, showing general magnification, showing region of the crack tip.

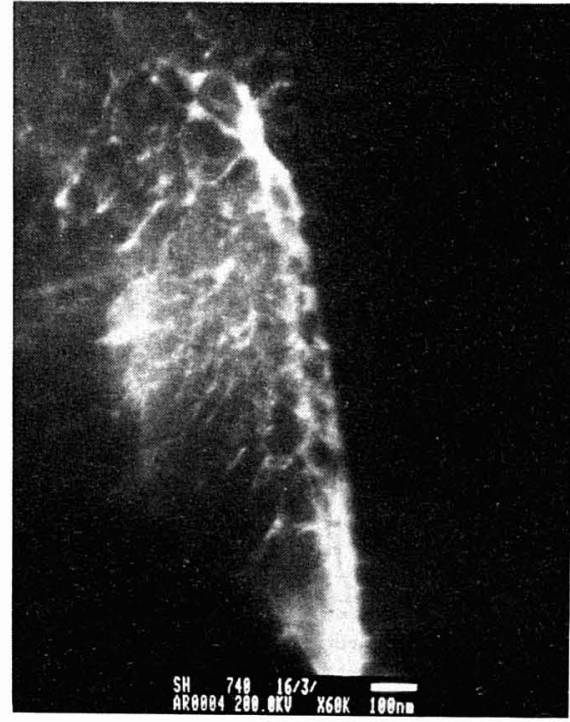

glass at a crack tip. (a) Low microcrack configuration. (b) High the glassy phase in the 

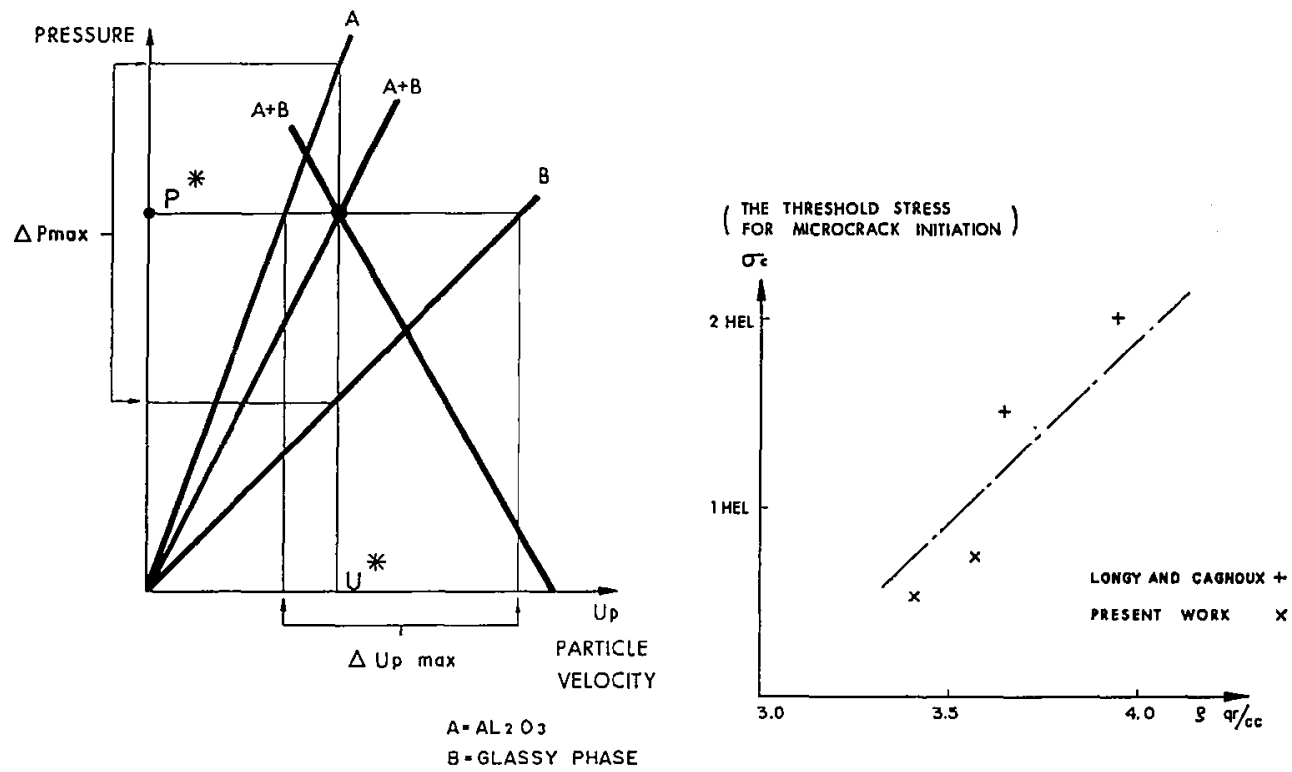

Fig. 8 - Microdynamic model of the effect of impedance mismatch.

Fig. 9 - Threshold for microcrack formation in units of the HEL as a function of density for glasscontaining aluminas.

\section{REFERENCES}

/1/ Rosenberg, Z, and Yeshurun. Y.. J.Appl.Phys. 58 (1985) 3077.

12/ Munson, D. and Lawrence, R.J., J.Appl.Phys. 50 (1979) 6272 .

/3/ Grady, D.E., J.Phys.Chem. Solids (to be published).

/4/ Longy, F. and Cagnoux. J.. Proc. Int.Conf. on Impact Loading \& Dynamic Behaviour of Materials (Bremen, 1987).

/5/ Yeshurun, Y.. Brandon, D.G. and Rosenberg, Z., Proc. Int.Conf. on Impact Loading \& Dynamic Behaviour of Materials (Bremen, 1987).

16/ DeCarli, P.S. and Meyers. M.A., "Shockwaves and High Strain-Rate Phenomena in Metals". Ed. M.Meyers and L.E.Murr, Chap.22, Plenum Press (1981).

17/Tsou, F.K.. "Dynamic Response of Material to Intense Impulsive Loading:, Ed. P.C.Chou and A.K.Hopkins. Air Force Materials Laboratory (1979).

/8/ Nielsen, L.F., Matls.Sci.Eng. 52 (1982) 39. 